\title{
Experiencing Diversity Management In Alaska Through Cultural Attunement At The Lilly Arctic Institute On Innovations And Excellence In Teaching
}

Larry N. Roberts, University of Alaska Fairbanks, USA

\begin{abstract}
In rural and frontier Alaska, the root network of our entire health services system is a collective of local paraprofessionals. Historically, however, beyond the paraprofessional level relatively few Alaska Natives have held credentialed or degree level positions. Enveloped in Alaska Native cultures and in concert with the wisdom of Elders, the University of Alaska Fairbanks has developed a successful and progressive education pathway for growing our own culturally competent or "attuned" behavioral health providers. As result of nearly 20 years of workforce development experience in Alaska, the Lilly Arctic Institute on Innovations and Excellence in Teaching was established to enhance educators and trainers skills in helping adult learners advance in their respective health careers. Setting this institute apart from most other similar conferences is the dynamic guidance of its respected Native Elders.
\end{abstract}

Keywords/phrases: Adult learners, Authentic learning, Behavioral health workforce, Cohort model, Cultural attunement, Excellence in teaching, Experiential learning, Frontier Alaska, Growing our own, Learning community, Lilly Arctic Institute, Native Elders, Rural Alaska, Talking Circle

\section{INTRODUCTION}

n many ways Alaska is unique in its challenges to provide behavioral health services to its rural and
frontier communities. Small community size and insufficient resources limit the availability of even the
most basic of mental health services for many residents. About $60 \%$ of Alaska's 690,000 population lives in or near the three largely urban boroughs encompassing Anchorage, Fairbanks, and Juneau. The remaining $40 \%$ or roughly 276,000 live throughout rural, frontier, or "bush" Alaska in a geographical region nearly $2 \frac{1}{2}$ times the size of Texas. Alaska's rural regions are primarily organized as city communities and villages. In addition to the 3 larger boroughs, the State of Alaska identifies 39 city communities and 200 village councils grouped under 12 Alaska Native Regional corporations. The populations in these communities vary from an estimated 50 to 13,500 with an average of 1,600 .

Access to mental health services is further limited due to the expansive state size-to-population ratio, the challenging geography and climate, and the lack of a road system for most of rural and frontier Alaska. Access to health services is not measured in terms of how many miles someone has to drive to get help. Rather, for the majority of rural residents it is measured by how long someone must fly to get services or how long someone must fly to provide services. It is also measured in terms of how much it costs to access, provide and maintain services. When we think about the inconvenience of having to drive 30, 50, or even 100 miles in rural America to access services, the fact of not having roads nor services within a drivable reach is noteworthy and a defining characteristic for frontier Alaska.

Historically and through present day, available services are frequently discontinuous due to a high turn over of the professional workforce. In many regions of the state there is a revolving door of professional providers. In most parts of the state beyond the paraprofessional level, there has been no educational pathway nor programs that train 
and advance local people into professional provider roles.

In response to the unique challenges of providing behavioral health services in rural and frontier Alaska, the University of Alaska Fairbanks has developed an educational pathway to "grow our own" culturally competent workforce. Although we continue to design and provide education and training for new and emerging professionals in our state, our first priority is to empower local residents and natural practitioners of culture as the professional behavioral health workforce. Building on the ever present and successful paraprofessional network, Alaska Natives and other rural residents can now advance seamlessly from a one year certificate (30-34 university credits) program through bachelor degrees in social work, psychology, human services and rural development. Within the University of Alaska system, this educational pathway extends through masters degrees in either social work or rural development or to a Ph.D. in Psychology.

One way to enter this behavioral health workforce educational pathway can be via traditional formal education processes, including simply enrolling in and being accepted into a certificate or degree program. Rural and frontier students can relocate to one of our central campuses in Fairbanks, Anchorage, and Juneau for access to full degree programs or attend any one of a number of our community campuses to work on respective general academic requirements before then having to relocate to complete targeted degrees in behavioral health, e.g., human services, social work, and psychology. This traditional academic gateway to behavioral health preparation, however, has not yielded a significant number of enrollments, graduates, nor workforce for rural and frontier Alaska. Alaska Natives and other rural residents interested in health careers find it most difficult to leave their home communities in pursuit of formal education and extended training. Some of the obstacles to a traditional education include the cost of education itself, the need to work and provide for self and family, the disruption of the basic and honored family unit when someone leaves for any amount of time, the ill preparedness for academic work (including limited success with public education and the cultural shock of moving from village life to urban or college life), and the perceived relevancy of academic curriculum and its practical application at home.

\section{THE MODEL}

By May of 2010, the University of Alaska Fairbanks, College of Rural \& Community Development, will have graduated over 28 cohorts of behavioral health practitioners at the certificate level in its seminal Rural Human Services (RHS) Program. Over $90 \%$ of these graduates are Alaska Natives who reside and work in rural or frontier Alaska. In 2002, the model was adapted at the Associate of Applied Sciences Human Services (HUMS) degree level to articulate with the RHS certificate graduates.

In 2004, the model was again adapted for students interested in continuing onto the bachelor's degree in social work. In contrast to our statewide distance education gateway to the behavioral health workforce that offers the more traditional academic programming, albeit primarily through audio conference classrooms with approximately $30 \%$ Alaska Native enrollment, the cohort academic gateway or ABC model reflects a 95\% Alaska Native enrollment and an overall completion rate of near $75 \%$.

What sets this educational pathway apart from previous and more traditional university educational programs is its attention to the wisdom of Elders, its holistic approach to wellness including attention to the spiritual realm, understanding and the practice of both traditional and non-traditional treatment modalities, and its facilitation as an adult learning experience. This Elders-assisted, cohort educational model is operationally framed as the $\mathbf{A B C}$ model and as follows: Accelerated Access to education and training; Blended delivery of modalities, approaches, and teachers; and as a Community or Cohort of adult learners.

The ABC model has evolved over time following its first appearance as a pilot education program in 1993. For three intensive weeks, 30 students met with a cadre of teachers and Elders in the basement of the Tanana Chiefs Conference regional health corporation building in Fairbanks. In terms of this model, intensive makes reference to the 50+ hours per week of instruction and learning activities, as well as to the periodic attention to more intense subject matter and experience related to topics such as grief recovery, domestic violence and suicide. It also reflects an intense community sense that develops from being together so long and so dynamically for these week or multiweek sessions. 
At the end of that first pilot session and reinforced in the field for the following 15 years, several elements and processes emerged or were reaffirmed that define the parameters of our present model. Some of these include:

1) Native Elders are active and equal members of the teaching team. They also serve as mentors for both instructors and students. Where previously Elders were many times invited to open meetings and trainings with a prayer or story, they were not expected to participate fully in sessions, presentations, and discussions.

2) A "Talking Circle" (or Circle of Talk) format was reaffirmed as a productive and culturally comfortable group facilitation practice when processing certain materials and experiences.

3) Attention to personal development and healing greatly enhanced the learning process.

4) Attention to the whole person including the spiritual realm and within the context of community and culture were paramount to the learner's commitment to the transfer of knowledge to practice.

5) The active processing of feelings is a valued and protected right for learners who work in the field of behavioral health, i.e., academic study can more often than not trigger emotional response and that requires attention to the emotional realm.

6) Learning as a community or cohort is consistent with rural and frontier culture. Rather than participating competitively as individual class members, everyone is committed to the success of all classmates as well as to the group as a learning community.

7) Interactive, experiential learning with application to real life and frequent opportunity for reflection are best teaching practices for our students.

8) Adults should be respected as adult learners. Teachers are more "guides on the side than sages on the stages."(Education is more about learning than it is about teaching.)

9) The practice of patience is an important virtue in the development of a learning community and environment.

\section{ELDERS}

Depending on someone's background, the term "elder" conjures a variety of meanings and mental pictures. In Alaska, when we refer to an elder we regularly capitalize the word as "Elder' when we are referring to a honored and respected life mentor or "wisdom keeper" who in most instances just happens to be an older adult. Becoming recognized as an Elder is a natural community process that rarely involves any formal announcement or declaration ceremony. A person does not apply to become an Elder, but increasingly over time, emerging Elders are noted for characteristics such wisdom and common sense, sensitive and even passionate expressions of heart, a sense of purpose, living a life in harmony and balance, commitment to culture and community, a love for learning and sharing of what they have learned, and even humor. While each cultural region will understand these characteristics differently, collectively Elders are generally recognized as being older adults who are good human beings. Fondly, two terms that are frequently used to describe an Elder is that "Elders are older people with the eyes of a child" and in academia, "Elders are true life-long learners.

\section{OTHER APPLICATIONS OF THE MODEL}

The Elders assisted, cohort model of teaching was developed specifically to help Alaska "grow its own" rural behavioral health workforce from within its own population base. Elements of this model have also been successful in earlier health education and rural education and development programs. However, following its more recent success in building a rural behavioral health workforce, it has been applied to other disciplines of study including early childhood education, teacher education, and allied health. Within each of these disciplines, students also successfully completed general education requirements like English, math, psychology, and the sciences. Because of the solid educational elements practice characteristic of this model, its application to other disciplines and fields of 
study should be possible especially when offered within the respective cultural context (ethnic as well as discipline) and with the advantage of respected Elders or mentors.

\section{THE ANNUAL INSTITUTE}

The Lilly Arctic Institute on Innovations and Excellence in Teaching (LAI) is held during the first week in March of each year during the crisp last days of the winter season in Fairbanks, Alaska on odd numbered years and at more rural locations on even numbered years. While the days are getting longer and thus the long arctic nights are less of an issue for the locals, the northern lights can still be seen dancing overhead on most clear nights and it is still cold enough to behold ice carving and dog mushing competitions and festivities for a few more weeks. In 2008, the institute's theme was Celebrating Cultural Attunement and Adult Learning. In 2009. the unifying theme was Celebrating Authentic Learning. However, celebrating cultural attunement and authentic adult learning have been the founding threads that define this northern gathering since its inception in 2006. Drawing on the lessons learned from our behavioral health workforce pathways programs, the LAI was developed to help prepare educators and others who facilitate learning experiences for rural Alaskans and others that work with diverse cultural settings. Central to the design that sets it apart from other institutes and conferences of this genre is LAI's incorporation of the teachings and participation of Alaska Native Elders.

With the dawning of each day, each session begins with blessings and guiding words from honored Elders. This year's institute with its dedicated focus on authentic learning benefited from the teachings of five Elders including Frank Haldane, Tsimshian; Elizabeth Fleagle, Inupiat; Ralph Johnson, Yupik; Sam Smith, Cu'pik; and from Fairbanks, Elder advocate, Erma Belz. One of the primary differences, however, in this type of gathering has been the Elders' continued and active participation throughout each session of the three day event. In contrast and heretofore, while it has been common practice to invite noted Elders to open similar conferences with a blessing, Elders themselves were rarely expected to participate in the subsequent plenary and break out sessions.

Thanks largely to the role of the Elders, the LAI has rapidly grown from its original purpose of providing an in-state event for university professionals to becoming a national level conference on culturally attuned and adult focused higher education and training.

Drawing in a wide array of presenters from throughout the U.S. as well within Alaska itself, participants to this year's institute represented a number of states including representatives from several community colleges and universities, tribal organizations, public fields, and region health corporations.

The theme of our March 3-5, 2010 LAI is Celebrating the Learning Community \& the Community of Learners and will highlight among other topics the dynamics, practice, and advantages of creating and supporting learning communities across all learning approaches and learning environments.This year's LAI will be in Valdez, Alaska. For more information on LAI 2010, go to HYPERLINK "http://www.uaf.edu/arbhta/" www.uaf.edu/arbhta/ or contact Larry Roberts, Institute Director at lnroberts@alaska.edu or 907/474-1913.

\section{AUTHOR INFORMATION}

Larry N. Roberts,M.Ed. is Associate Professor of Human Services at the University of Alaska Fairbanks. His appointment is in the Alaska Rural Behavioral Health Training Academy where he is the Project Investigator and Coordinator for the Work-based Learning program, Director of the Lilly Arctic Institute on Innovations and Excellence in Teaching, and training faculty with the Geriatric Education Center. He has lived and worked in rural Alaska for over 25 years. 